\title{
E-waste polycyclic aromatic hydrocarbons (PAHs) exposure lead to child gut-mucosal inflammation and adaptive immune response
}

\section{Guangcan Chen}

Shantou University Medical College

\section{Xia Huo}

Jinan University School of Environment

Xiuli Luo

Shantou University Medical College

\section{Zhiheng Cheng}

University Medical Centre Groningen: Universitair Medisch Centrum Groningen

\section{Yuling Zhang}

Shantou University Medical College

\section{Xijin Xu ( $\nabla$ xuxj@stu.edu.cn )}

Shantou University Medical College https://orcid.org/0000-0003-2094-3164

\section{Research Article}

Keywords: Polycyclic aromatic hydrocarbon, E-waste, Secretory immunoglobulin A, Sialyl Lewis A, Intestinal immunity, Adaptive immunity

Posted Date: March 16th, 2021

DOl: https://doi.org/10.21203/rs.3.rs-272669/v1

License: (9) This work is licensed under a Creative Commons Attribution 4.0 International License. Read Full License 


\section{Abstract}

Polycyclic aromatic hydrocarbon (PAH) exposure alters immunological responses. Research concerning PAH exposure on intestinal immunity of children in electronic waste (e-waste) areas is scarce. The aim of this study was to evaluate the effects of polycyclic aromatic hydrocarbons (PAHs) pollutants on intestinal mucosal immunity of children in e-waste areas. Results showed higher hydroxylated PAH (OHPAH) concentrations in e-waste-exposed children, accompanied with higher sialyl Lewis A (SLA) level, absolute lymphocyte and monocyte counts, decreased of percentage of $\mathrm{CD} 4^{+} \mathrm{T}$ cells, and had a higher risk of diarrhea. OH-PAH concentrations were negative with child growth. 1-OHNap mediated through WBCs, along with 1-OHPyr were both correlated with an increase SLA concentration. 2-OHFlu, 1-OHPhe, 2OHPhe, 1-OHPyr and 6-OHChr were positively correlated with secretory immunoglobulin A (slgA) concentration. Our results indicated that PAH pollutants caused inflammation, affected the intestinal epithelium, and led to transformation of microfold cell ( $M$ cell). $M$ cells initiating mucosal immune responses and the subsequent increasing slgA production might be an adaptive immune respond of children in the e-waste areas. To our knowledge, this is the first study of PAH exposure on children intestinal immunity in e-waste area, showing that PAH exposure plays a negative role in child growth and impairs the intestinal immune function.

\section{Introduction}

Polycyclic aromatic hydrocarbons (PAHs) are listed as a kind of priority environmental pollutants with public health concerns (Ramirez et al., 2011). Existing studies show that diabetes, metabolic syndrome, cardiovascular disease, asthma, dyslipidemia, hematology,neurobehavioral disorders and cancer are related to exposure to PAHs (Hu et al., 2018a; Karimi et al., 2015; Kim et al., 2021; Manoli et al., 2016; Rengarajan et al., 2015; Roshandel et al., 2012; Yang et al., 2014; Yilmaz et al., 2007; Wang et al., 2020a; Zhang et al., 2020a). Studies also reveal a link between PAHs and gastrointestinal (GI) symptoms and diseases, and even GI tumors (Bansal and Kim, 2015; Diggs et al., 2011; Gunter et al., 2007; Henkler et al., 2012; Poirier et al., 2019; Prince, 2015; Roshandel et al., 2012). These findings strongly suggest an association between PAH exposure and impairment of the GI tract.

The $\mathrm{Gl}$ tract is the main organ providing an internal barrier against environmental exposure, and plays an important role in the physical and immune barriers to entry of harmful compounds in the body (Arnal and Lalles, 2016; Ghosh et al., 2020). Breaking the epithelial barrier or even a minor disorder can lead to serious pathological consequences, including infection and inflammation (Citi, 2018). Mounting studies imply an association between PAHs and microflora. By altering bacterial communities and interrupting the function of the intestinal microflora, PAHs can cause intestinal inflammatory disorders and immune respond (Defois et al., 2018; Mantey et al., 2014; Roslund et al., 2019; Roslund et al., 2020). In vitro and in vivo studies have also shown that PAHs can affect the immune system (Abdel-Shafy and Mansour, 2016; Kim et al., 2013). However, very few studies have investigated alterations of the GI immune system (Abdel-Shafy and Mansour, 2016). 
To maintain gut immune homeostasis, there are multiple layers of defense in the intestinal mucosa, including innate and adaptive defenses (Ren et al., 2016). M cells mediate antigen uptake and specific secretory immunoglobulin A (slgA) production which play a vital role in adaptive defenses (Kobayashi et al., 2019). M cells initiate mucosal immune responses by active phagocytosis and transcytosis of luminal bacteria and antigen presentation to dendritic cells (DCs) in the underlying lymphoid follicles (Ohno, 2016). T cells and B cells are activated when DCs present antigen. Mucosal B cells then undergo IgA class switch recombination (CSR), migrate into the lamina propria and mature into IgA-producing plasma cells to produce IgA (Li et al., 2020; Liu et al., 2013). IgA binds to the polymeric immunoglobulin receptor (plgR) and is transported across the cell to the lumen to form the molecule slgA (Li et al., 2020).

SLA is a lectin largely restricted to M cells within epithelial tissues (Giannasca et al., 1999; Ragupathi et al., 2009). During inflammation, $M$ cells are induced in the intestinal tract and their number increases in inflamed mucosa (Lugering et al., 2004). In vitro, epithelial cells are transformed to cells with an M-celllike morphology and up-regulate SLA antigen production (Gullberg et al., 2000). It has been observed that an increase in IgA level is associated with the increase in SLA level in colon disease (larumov et al., 1998; Jasim et al., 2008). All these results suggest a link between M-cell differentiation and slgA production in intestinal inflammation.

Although epidemiological studies have revealed a close link between PAH exposure and human digestive disease, the underlying mechanisms remain unexplored (Mantey et al., 2014; Shiue, 2016). Previous studies on PAH exposure and serum IgA expression are not consistent (Gao et al., 2014; Jeng et al., 2011; Karakaya et al., 1999; Szczeklik et al., 1994). Currently, limited studies of PAH exposure and human intestinal immunity have been about occupational exposure, and most of those studies have focused on $\lg A$ levels. Since serum $\lg A$ is monomolecular and slgA is multimolecular, serum IgA cannot fully reflect the mucosal immunity (Li et al., 2020). According to the literature, most serum slgA probably origin from the digestive tract and its levels of determination can be the most direct way to assess the amount of slgA secretion in digestive tract (Pérez-Griera et al., 2017). The association between PAH exposure and serum sigA level has not been studied, especially for the children in e-waste areas.

Guiyu is an e-waste recycling town located in Guangdong province, in southeast China, and has a more than 40-year history of e-waste disposal (Zeng et al., 2018). It has been reported that environmental medias surrounding e-waste dismantling areas extremely contaminated by PAHs from thermal recycling activities (Liu et al., 2020; Wang et al., 2020a). Our previous studies have shown that local residents in Guiyu are exposed to PAHs and have health problems (Guo et al., 2012; Huang et al., 2020; Wang et al., 2020a; Xu et al., 2013; Xu et al., 2015; Zeng et al., 2020; Zheng et al., 2019). Previous studies shows PAH exposure affects immune system (Abdel-Shafy and Mansour, 2016; Burchiel and Luster, 2001; Dupuy et al., 2014; Ekhator et al., 2018; Gou et al., 2017; Kim et al., 2013). To better understand the relationship between PAH exposure and intestinal immunity, we recruited children from Guiyu and Haojiang (as a reference area located $31.6 \mathrm{~km}$ to the east of Guiyu) for the current study. We hypothesize that PAH exposure may cause GI tract inflammation and lead to M cell differentiation, which may consequently alter intestinal immunity. 


\section{Materials And Methods}

\subsection{Study population}

A total of 232 children (2-7 years old), all residents in Guiyu and Haojiang for more than one year, were included in this study (exposed group $n=119$ vs. reference group $n=113$ ). All children were recruited from two kindergartens during November to December 2018, and were free from general medical conditions and diseases. Apart from e-waste pollution, the two regions are very similar in ethnicity, cultural background and population. Informed consent with a questionnaire on general characteristics, dwelling environment, children's living habits, family history, monthly household income, and parental educational level was obtained from the parents or guardians of all participants. This study was approved by the Human Ethics Committee of Shantou University Medical College, China. As previously described, fasting venous blood was collected by a nurse. The whole blood was used to measure immune cells and serum was used to measure SLA and slgA. The rest of the serum was aliquoted and stored at $-80^{\circ} \mathrm{C}$ until analysis (Zheng et al. , 2019).

\subsection{Measurement of PAH metabolites in urine}

Eleven urinary PAH metabolites [1-hydroxynaphthalene (1-OHNap), 2-hydroxynaphthalene (2-OHNap), 2hydroxyfluorene (2-OHFlu), 9-hydroxyfluorene (9-OHFlu), 1-hydroxyphenanthrene (1-OHPhe), 2-

hydroxyphenanthrene (2-OHPhe), 3-hydroxyphenanthrene (3-OHPhe), 4-hydroxyphenanthrene (4-OHPhe), 9-hydroxyphenanthrene (9-OHPhe), 1-hydroxypyrene (1-OHPyr) and 6-hydroxychrysene (6-OHChr)] were measured by gas chromatography/mass spectrometry (GC/MS, 7890A-5975C Agilent Technologies) according to previous studies, with electron ionization used in selected ion monitoring mode (Campo et al., 2008; Cheng et al., 2020; Dai et al., 2019; Huang et al., 2020; Huo et al., 2019; Wang et al., 2020b; Zheng et al., 2019). Methods for QA/QC were based on our previously published methods with minor modifications (Cheng et al., 2020; Dai et al., 2019). SOH-PAHs was defined as the sum of the eleven congeners in urine. SOHNap was defined as the sum of 1-OHNap and 2-OHNap. SOHFlu was defined as the sum of 2-OHFlu and 9-OHFlu. SOHPhe was defined as the sum of five OHPhe congeners in urine.

\subsection{General physical tests and biological measurements}

General physical examinations, including height, weight and chest circumference, were performed by trained physician as described previously (Dai et al., 2019; Wang et al., 2020b; Xu et al., 2015; Zeng et al., 2020). A Sysmex XE-2100 automatic hematology analyzer was used for determining the white blood cell count in peripheral blood. The serum levels of SLA and slgA were measured with a CA19-9/Sialyl Lewis A (Human) ELISA Kit (KA0207, Abnova, Taiwan) and a Secretory IgA (Human) ELISA Kit (KA3980, Abnova, Taiwan). Sensitivity was $10 \mathrm{U} / \mathrm{mL}$ and $0.6 \mu \mathrm{g} / \mathrm{mL}$, respectively. ELISAs were performed following the manufacturer's instructions.

\subsection{Flow Cytometry}


To determine the $\mathrm{B}$ lymphocytes $\left(\mathrm{CD}^{-} \mathrm{CD} 19^{+}\right)$and $\mathrm{CD} 3^{+} \mathrm{CD} 4^{+} \mathrm{CD} 8^{-} \mathrm{T}\left(\mathrm{CD} 4^{+} \mathrm{T}\right.$ cells) cells phenotype, $100 \mu \mathrm{L}$ whole blood was mixed with appropriate volume of the following monoclonal antibodies: CD3-APC-Cy7, CD4-PE-CF594, CD8-FITC and CD19-PE-Cy7 (BD Bioscience, USA), and incubated for 15 min away from light at room temperature, then $2 \mathrm{~mL}$ of $1 \times$ lysing solution (BD Bioscience, USA) was added and vortexed gently, and incubated for 10 min away from light at room temperature. After centrifugation at $500 \mathrm{~g}$ for 5 min, the supernatant was discarded, the cells were washed twice with $2 \mathrm{~mL}$ of $1 \times$ PBS, followed by resuspension in $500 \mu \mathrm{L}$ of $1 \times$ PBS. Cells were analyzed by FACS using an CYTEK Aurora flowcytometer (CYTEK Biosciences inc., USA). Data was analyzed with Spectro Flo (CYTEK Biosciences inc., USA).

\subsection{Statistical analysis}

Data were analyzed by SPSS (Statistical Package for Social Sciences) version 22. All data were expressed as median and ranges or mean and standard deviation. We used the Pearson chi-square test, independent sample $t$-test, or Mann-Whitney $U$ test to assess demographic and other characteristic differences between the two groups. Spearman's correlation analysis was performed to assess the relevant factors contributing to urinary PAH metabolites and the effects of PAH metabolites on the other indicators. Variables with skewed distributions were In-transformed prior to regression and mediation analysis. $P<0.05$ was set as the significance level in a two-tailed test.

\section{Results}

\subsection{Basic characteristics of the study population}

A total of 232 children were enrolled in the study (Table 1). Children in the two groups have no significant differences in gender and age $(P>0.05)$. The weight, height, chest circumference and BMI of children are lower in the exposed group $(P<0.05)$. Children in the exposed group reside in a poorer residential environment, and the majority children reside in a residence near a road or an e-waste site, or live in family workshops and have a family member who smoking (all $P<0.05$ ). All these provide potential exposure to environmental pollution. The education level of the parents and monthly household income are lower for exposed children. Moreover, children in the exposed group more commonly display irritable bowel symptoms, diarrhea (more than three movements of loose stools a day) compared to the reference [odds ratio $(\mathrm{OR})=2.21 ; 95 \% \mathrm{Cl}: 1.16,4.21 ; \mathrm{p}$-value $=0.014$ ]

\subsection{Urinary PAH metabolite concentrations and factors influencing $\mathrm{OH}-\mathrm{PAHs}$}

Except for 9-OHFlu, 2-OHPhe, 3-OHPhe and 9-OHPhe, the other seven urinary $\mathrm{OH}-\mathrm{PAH}$ concentrations are significantly higher in the exposed than the reference group (Table 2). Spearman correlation analysis showed that most urinary PAH metabolites are highly correlated with BMI, height, weight, and chest circumference (Table 3 ). In order to investigate the potential influencing factors of PAH exposure, a Spearman correlation analysis is performed (Table 4). Results show that urinary 1-OHNap concentration is positively correlated with e-waste contact, family workshops, residence within $50 \mathrm{~m}$ from an e-waste site and family member smoking. Urinary 1-OHNap, SOHNap and SOHPAHs concentrations are negatively 
correlated with distance between residence and road, and urinary 1-OHNap, 1-OHPyr, SOHNap, SOHPhe, and SOHPAH concentrations are negatively correlated with the educational level of children's parents.

\subsection{Peripheral leukocyte count and associations between urinary OH-PAHs}

As shown in Fig. 1, the absolute lymphocyte and monocyte counts in the exposed group children are significantly higher than the reference group (both $P<0.05$ ). Both white blood cells (WBCs) and absolute neutrophil counts of children in the exposed group tended to be higher than the reference group, but there is no significant difference (both $P>0.05$ ). Spearman correlation analysis show that urinary 1-OHNap is positive correlated with WBCs and the absolute lymphocyte and monocyte counts $\left(r_{s}=0.142, r_{s}=0.147\right.$ and $r_{s}=0.206$ respectively, all $P<0.05$ ), urinary $1-0 H P y r$ is positive correlated with the absolute lymphocyte counts $\left(r_{\mathrm{s}}=0.132, P<0.05\right)$

\subsection{Comparison of SLA, sIgA concentration and immune cells}

The SLA concentration of children in the exposed group is significantly higher compared with the reference group (Fig. 2, $P<0.05$ ). The percentage of $C D 4^{+} \mathrm{T}$ cells is lower in the exposed group than the reference group $(P<0.05)$. The percentage of $\mathrm{B}$ cells tended to be higher in the exposed children, but no significance difference is obtained when compared with the reference $(49.83 \%$ vs. $46.58 \%, P>0.05)$.

\subsection{SLA and slgA concentration of the 4 and 5-year-old children}

Due to the fact that children included in this study had sample bias, we only analyzed the subgroup of 4 and 5-year-old children from the two areas (Fig.3). Results show that for the 4-year-old children, both SLA and slgA are both higher in the exposed group than reference (both $P<0.05$ ), but no significance difference in the 5-year-old children. The slgA concentration of 5-year-old children is lower than 4-years in the exposed group $(P<0.05)$, but no significance difference in the reference group.

\subsection{Urinary PAH metabolite concentrations of the 4- and 5-year-old children}

In the reference group, urinary SOHPAHs, 2-OHNap, 2-OHFlu, 1-OHPhe, 2-OHPhe, 4-OHPhe, 9-OHPh, 1$\mathrm{OHPyr}$, 6-OHCh, SOHNap and SOHPhe concentrations are higher in the 4-year-old group compared with the 5-year-old group (all $P<0.05$ ). In the exposed area, the urinary $\mathrm{OH}-\mathrm{PAH}$ concentrations between the two age groups show no significant difference (Fig.4).

\subsection{Associations between urinary OH-PAHs with slgA, SLA, and B cell percentage}

A multivariable linear regression model was performed to identify the contributions of OH-PAHs to slgA, SLA and B cell percentage in children (Fig. 5). Unadjusted regression analysis shows that 2-OHFlu, 1OHPhe, 2-OHPhe, 1-OHPyr and 6-OHChr are positively correlated with slgA concentration, 1-OHPyr is positively correlated with SLA concentration and 1-OHNap, 2-OHNap, 1-OHPyr, SOHNap and SOH-PAHs are positively correlated with the percentage of $\mathrm{B}$ cells. The correlations between 1-OHPhe, 2-OHPhe, 1OHPyr, 6-OHChr and slgA concentration, 1-OHPyr level and SLA concentration, and 1-OHNap and B cell 
percentage remain significant after further adjustment for gender, age, BMI, contact with e-waste, parental educational level, and monthly household income.

\subsection{Mediation effect analysis}

Mediation model analysis shows that WBC concentration is a mediator in the correlation of 1-OHNap and SLA level (Fig. 6). In increasing WBC concentration, each 1-unit-increase in 1-OHNap concentration is estimated to be correlated with a $0.020 \mu \mathrm{g} / \mathrm{mL}$ increase in SLA level. However, the direct effect of 1OHNap on SLA level is not statically significant in mediation effect analysis, indicating that WBC concentration is completely responsible for the mediation.

\section{Discussion}

In this study, we find that exposure group children had higher risk for diarrhea [odds ratio $(O R)=2.21$ ] compared to the reference children. PAH exposure is negatively correlates with BMI, height, weight and chest circumference of the children. Most of hydroxylated polycyclic aromatic hydrocarbons (OH-PAHs) concentrations of children were higher in the exposed group and positively correlates with inflammation cells and intestinal immune biomarkers. Our results demonstrate that PAH exposure may be associated with gastrointestinal inflammation and immune responses. To our knowledge, this is the first study to provide evidence about the relationship between PAH exposure and intestinal immunity.

Urinary levels of $\mathrm{OH}-\mathrm{PAHs}$ are widely used as a biomarker for estimating human exposure to PAHs from all routes of exogenous compounds (Lu et al., 2016; Yang et al., 2016). In this study, eight of eleven urinary $\mathrm{OH}-\mathrm{PAH}$ concentrations of children are significantly higher in the exposed group than in the reference group, which is consistent with our previous studies indicating that children from e-waste recycling areas have elevated OH-PAH levels (Dai et al., 2019; Wang et al., 2020b; Xu et al., 2015; Zeng et al., 2020; Zheng et al., 2019). We find that 1-OHNap is negative with BMI, whereas most of the OH-PAHs negatively correlate with height, weight, and chest circumference, suggesting that PAH exposure has adverse effects on the development of children. As the recent studies described, we used biomonitoring studies to reveal the relationships between urinary PAH metabolite levels and several lifestyle and/or demographic variables (Keir et al., 2020; Oliveira et al., 2020). The results show that urinary 1-OHNap metabolites are positively correlated with e-waste contact, family workshops, residence within $50 \mathrm{~m}$ from an e-waste site and family member smoking. We also find that OH-PAHs are negatively correlated with parental education levels, which corroborates previous studies suggesting that child health is associated with parental educational attainment reflecting knowledge-related assets, as well as other health-related characteristics (Carozza et al., 2010; Faught et al., 2019) . In total, our findings indicate that pollution in ewaste areas and living habits affect children's urinary $\mathrm{OH}-\mathrm{PAH}$ levels and have adverse effects on child growth.

Many studies have reported associations of PAH exposure and inflammation (Alshaarawy et al., 2013; Kamal et al., 2014; Zhang et al., 2020b). PAH exposure is known to induce oxidative stress and promote the production of reactive oxygen species (Dupuy et al., 2014; Huang et al., 2018; Jeng et al., 2011; Lu et 
al., 2016; Yang et al., 2014; Yilmaz et al., 2007; Zhang et al 2020b). The results of the present study showed that 1-OHNap and 1-OHPyr correlate with inflammatory cells and both compounds are elevated in the exposed group, consistent with our prior studies demonstrating that PAH exposure is associated with inflammation (Cheng et al., 2020; Dai et al., 2019; Zheng et al., 2019) .

Relationship between PAH exposure and GI inflammation has been poorly studied in human. An animal study has indicated that PAHs can be metabolized and the metabolic products secreted into the GI tract to cause toxicity to epithelial cells (Mantey et al., 2014) . Except for the direct impact on the digestive tract, PAHs can also affect intestinal flora to cause intestinal inflammatory disorders by secreting toxic metabolic products, altering bacterial communities and interrupting the functions of the intestinal microflora (Defois et al., 2018; Mantey et al., 2014; Roslund et al., 2019; Roslund et al., 2020). Under inflammatory conditions, intestinal epithelial cells may be converted to M cells (Gullberg and Soderholm, 2006; Lugering et al., 2004). We applied a linear mediation model with adjustment for factors to quantify the association between PAH exposure and SLA expression. Results show that 1-OHPyr affects the SLA level directly while 1-OHNap affects the SLA level through WBC mediation. For each 1-unit increase in concentration of 1-OHPyr and 1-OHNap, the SLA concentration increases $0.093 \mu \mathrm{g} / \mathrm{mL}$ and 0.020 $\mu \mathrm{g} / \mathrm{mL}$, respectively. Collectively, our results suggest that PAH exposure may be linked to Gl inflammation and leads to $\mathrm{M}$ cell differentiation. Previous studies indicated that 1-OHNap present almost exclusively in vapor phase and is associated with inhalation exposure while 1-OHPyr as particulate matter with dietary exposure (Kim et al.,2021; Lao et al. , 2018; Manoli et al., 2016; Nethery et al., 2012; Onyemauwa et al., 2009). We speculate that atmospheric PAH exposure causes a systemic inflammatory reaction and impairs the epithelium of the GI tract, whereas dietary PAH exposure directly modulates the gastrointestinal immune response, and both lead to $\mathrm{M}$ cell differentiation in the intestinal epithelium, as manifested by increased SLA concentrations in children.

Diarrhea is the manifestation of a disturbed gut environment as a symptom of an intestinal tract infection usually caused by a host of pathogens, which most likely results from disturbances in antigenspecific mucosal immune responses (Dong et al., 2017; Nagai et al., 2019; Yaya et al., 2018). We find that children in exposure group had higher risk for diarrhea [odds ratio $(O R)=2.21$ ] compared to the reference. Previous studies have shown that PAH exposure was associated with suppression of T-cell proliferation and decreased the percentage of $\mathrm{CD} 4^{+} \mathrm{T}$ cells, while lower numbers of $\mathrm{CD} 4^{+} \mathrm{T}$ cells are predictive of chronic diarrhea (Gou et al., 2017; Lauer et al., 2019; Navin et al., 1999). In this study, the percentage of $\mathrm{CD} 4^{+} \mathrm{T}$ cells decrease in the exposed group may associate with PAH exposure, which may be the reason for the diarrhea in exposed children. The correlation and regression analysis for OHPAHs and B cells is also consistent with a prior study reporting that exposure to PAHs might affect the differentiation of $B$ cells (Huang et al., 2018). Together, our results suggest that PAH exposure may impair intestinal immune function, raise the risk of $\mathrm{Gl}$ tract pathogen infection, lead children diarrhea and favor B-cell differentiation as an adaptive response.

Previous studies indicate that PAH exposure alters immunological responses and changes the expression of serum IgA. However, those results are not consistent. An increase of serum IgA level has been 
suggested in bitumen workers exposed to PAHs compared to the control group, but this disparity was not significant (Karakaya et al., 1999). By contrast, Jeng et al. (2011) found an inverse association between levels of PAHs and IgA (Jeng et al., 2011). Szczeklik et al. (1994) also found that workers chronically exposed to PAHs had depression of mean IgA levels (Szczeklik et al., 1994). Gao et al. (2014) showed that individuals exposed to high levels of PAHs had significantly lower mean IgA level (Gao et al., 2014). Limited studies about associations between PAH exposure and serum IgA expression have yielded inconsistent findings. All of those studies focused on adult occupational exposure, by analyzing the association between PAH exposure with serum IgA, which cannot totally reflect the mucosal immunity. According to the literature, serum slgA is presumed to be a reliable indicator of mucosal immunity and the increases levels are evidence of subclinical intestinal compromise (Arias et al., 2020; Pérez-Griera et al., 2017). Here we explored the relationship of PAH exposure and serum slgA in the children in an e-waste area, which has not been studied. Results show that 1-OHPhe, 2-OHPhe, 1-OHPyr and 6-OHChr are estimated to be correlated with an increase in slgA level, suggesting that PAH exposure might affect child mucosal immunity and elevate the level of serum slgA.

Younger children are more seriously exposed to PAHs because they prefer to play and crawl around on the floor and ground, and display hand-to-mouth behavior (Huang et al., 2019; Oliveira et al., 2019). Our results showing that the concentrations of most OHPAHs decrease in the 5-year-old children than 4-yearold children in the reference group, supports this suggestion. However, in the exposed group, no significant difference of OHPAH concentration was observed between the 4- and 5-year-old children. We speculate that the high urine OHPAH levels of children in e-waste area are associated with the high concentration of PAHs in the environment. Even though behavioral changes with age can reduce PAH exposure, the urinary $\mathrm{OH}-\mathrm{PAH}$ levels of older children remain high, indicating that environmental PAH pollution continues to pose a long-term serious threat to local children.

$M$ cells have critical roles in intestinal slgA production (Ren et al., 2016). For the 4-year-old, both SLA and slgA are significantly elevated in the exposed group. Depending on various parameters, PAHs exert complex effects on the immune system resulting in immune-suppression or immune-potentiation (AbdelShafy and Mansour, 2016). Low levels of PAH exposure may lead to immune enhancement or an adjuvant effect (Burchiel and Luster, 2001). In the current study, we found that PAH exposure increases children's slgA levels. The reason may be that occupational PAH exposure is more serious than life-style exposure of children in e-waste areas. In addition, children enrolled in this study are all healthy individuals, and the concentrations of PAHs are estimated to be low, even in the exposed group. The effects of low levels of PAHs on human health, particularly in children, are unknown (Ekhator et al., 2018). We speculate that the increase level of slgA might be an adaptive protective response of children to the external PAHs related to toxic intestinal inflammation, suggesting that mucosal immunity strengthens, to some degree, the protective mechanism against environmental irritants.

The limitations of this study are as follows. Firstly, though our study provides an association between PAHs and intestinal immune responses, this may not necessarily indicate a cause-and-effect relationship between PAH exposure and intestinal immune-mediated inflammation. Secondly, children included in this 
study have sample bias, due to the insufficient number of samples of 2-, 3- and 6-year-old children, we only compare the subgroups of 4- and 5-year-old children for some parameters. We are not able to determine the trend of the influence of PAHs on mucosal immunity, so a large-sample follow-up observation is necessary. Thirdly, there is a wide variety of toxic substances in e-waste site. We only analyze the effect of PAH metabolites on mucosal immunity, and only collected morning urine samples at one point. To confirm our findings, more samples of contaminants and multiple measurements of PAH metabolites are needed for analyze.

\section{Conclusion}

In summary, this is the first study to identify the relationship between mucosal immune response and PAH exposure of children from an e-waste area. The results show diarrhea occurs more often in e-wasteexposed children, and PAH exposure has adverse effects on child growth. We also find that PAH exposure causes inflammation and leads to $\mathrm{M}$ cell differentiation, with subsequently initiating an adaptive immune response by secreting slgA. Younger children are more susceptible to PAH exposure, especially in e-waste areas. These available data support the hypothesis that for young children in e-waste areas, low level of PAH exposure may lead to intestinal inflammation and alter the intestinal immune response, which may raise the risk of $\mathrm{Gl}$ tract pathogen infection, lead children diarrhea and affect development. The elevation of slgA levels may be a protective immune response to PAH exposure. Even behavioral changes with age can reduce $\mathrm{PAH}$ exposure, urinary $\mathrm{OH}-\mathrm{PAH}$ levels remain high in older children in e-waste areas, suggesting PAH exposure poses a long-term health threat to the local children. It is necessary to take more preventive measures to further reduce organic pollutant exposure in e-waste areas and pay more attention to protect children from e-waste contamination.

\section{Declarations}

\section{Acknowledgements}

We would like to thank Dr. Stanley Lin for his constructive comments and English language editing. Finally the authors are grateful to all the recruited children and their guardians for participating in this project.

\section{Author contributions}

GC: Conceptualization, Investigation, Formal analysis, Writing Original Draft. XL: Investigation, Formal analysis. ZC: Data Curation, Investigation. YZ: Investigation, Project administration. XX and XH: Review \& Editing, Supervision, Project administration, Funding acquisition, Formal analysis. All authors read and approved the final manuscript.

\section{Funding}

This work was supported by the National Natural Science Foundation of China (21876065). 
Availability of data and materials

The datasets used and/or analyzed during the current study are available from the corresponding author on reasonable request.

\section{Compliance with ethical standards}

Conflict of interest The authors declare that they have no conflict of interest

\section{Ethics approval}

This study was approved by the Human Ethics Committee of Shantou University Medical College, China. Informed consent was obtained from each child's parents or guardians.

Consent to participate All authors were participated in this work

Consent to publish All authors agree to publish.

\section{References}

Abdel-Shafy, H.,Mansour, M., 2016. A review on polycyclic aromatic hydrocarbons: Source, environmental impact, effect on human health and remediation. Egyptian Journal of Petroleum. 25, 107-123. https://doi.org/10.1016/j.ejpe.2015.03.011.

Alshaarawy, O.,Zhu, M.T.,Ducatman, A.,Conway, B.,Andrew, M.E., 2013. Polycyclic aromatic hydrocarbon biomarkers and serum markers of inflammation. A positive association that is more evident in men. Environ Res. 126, 98-104. https://doi.org/10.1016/j.envres.2013.07.006.

Arias, I.,Herrera, D.,Bautista-Molano, W.,Bello-Gualtero, J.M.,De Avila, J.,Salas-Cuestas, F.,Romero-Sánchez, C., 2020. Increasing of SIgA serum levels may reflect subclinical intestinal involvement in nonradiographic axial and peripheral spondyloarthritis. Clinical rheumatology. https://doi.org/10.1007/s10067-020-05369-w

Arnal, M.E.,Lalles, J.P., 2016. Gut epithelial inducible heat-shock proteins and their modulation by diet and the microbiota. Nutr Rev. 74, 181-197. https://doi.org/10.1093/nutrit/nuv104.

Bansal, V.,Kim, K.H., 2015. Review of PAH contamination in food products and their health hazards. Environ Int. 84, 26-38. https://doi.org/10.1016/j.envint.2015.06.016.

Burchiel, S.W.,Luster, M.I., 2001. Signaling by Environmental Polycyclic Aromatic Hydrocarbons in Human Lymphocytes. Clinical Immunology. 98, 2-10. https://doi.org/https://doi.org/10.1006/clim.2000.4934.

Campo, L.,Rossella, F.,Fustinoni, S., 2008. Development of a gas chromatography/mass spectrometry method to quantify several urinary monohydroxy metabolites of polycyclic aromatic hydrocarbons in 
occupationally exposed subjects. J Chromatogr B Analyt Technol Biomed Life Sci. 875, 531-540. https://doi.org/10.1016/j.j.jhromb.2008.10.017.

Carozza, S.E.,Puumala, S.E.,Chow, E.J.,Fox, E.E.,Horel, S.,Johnson, K.J.,McLaughlin, C.C.,Reynolds, P.,Von Behren, J.,Mueller, B.A.,Spector, L.G., 2010. Parental educational attainment as an indicator of socioeconomic status and risk of childhood cancers. Brit J Cancer. 103, 136-142. https://doi.org/10.1038/sj.bjc.6605732.

Cheng, Z.,Huo, X.,Dai, Y.,Lu, X.,Hylkema, M.N.,Xu, X., 2020. Elevated expression of AhR and NLRP3 link polycyclic aromatic hydrocarbon exposure to cytokine storm in preschool children. Environ Int. 139, 105720. https://doi.org/10.1016/j.envint.2020.105720.

Citi, S., 2018. Intestinal barriers protect against disease. Science. 359, 1097-1098. https://doi.org/10.1126/science.aat0835.

Dai, Y.,Huo, X.,Cheng, Z.,Wang, Q.,Zhang, Y.,Xu, X., 2019. Alterations in platelet indices link polycyclic aromatic hydrocarbons toxicity to low-grade inflammation in preschool children. Environ Int. 131, 105043. https://doi.org/10.1016/j.envint.2019.105043.

Defois, C.,Ratel, J.,Garrait, G.,Denis, S.,Le Goff, O.,Talvas, J.,Mosoni, P.,Engel, E.,Peyret, P., 2018. Food Chemicals Disrupt Human Gut Microbiota Activity And Impact Intestinal Homeostasis As Revealed By In Vitro Systems. Sci Rep. 8, 11006. https://doi.org/10.1038/s41598-018-29376-9.

Diggs, D.L.,Huderson, A.C.,Harris, K.L.,Myers, J.N.,Banks, L.D.,Rekhadevi, P.V.,Niaz, M.S.,Ramesh, A., 2011. Polycyclic aromatic hydrocarbons and digestive tract cancers: a perspective. J Environ Sci Health $\mathrm{C}$ Environ Carcinog Ecotoxicol Rev. 29, 324-357. https://doi.org/10.1080/10590501.2011.629974.

Dong, Y.L.,Han, Y.N.,Wang, Z.X.,Qin, Z.M.,Yang, C.Y.,Cao, J.,Chen, Y.X., 2017. Role of serotonin on the intestinal mucosal immune response to stress-induced diarrhea in weaning mice. Bmc Gastroenterol. 17. https://doi.org/10.1186/s12876-017-0634-5.

Dupuy, C.,Galland, C.,Devaux, A.,Bony, S.,Loizeau, V.,Danion, M.,Pichereau, V.,Fournier, M.,Laroche, J., 2014. Responses of the European flounder (Platichthys flesus) to a mixture of PAHs and PCBs in experimental conditions. Environmental science and pollution research international. 21, 13789-13803. https://doi.org/10.1007/s11356-014-2563-y.

Ekhator, O.C.,Udowelle, N.A.,Igbiri, S.,Asomugha, R.N.,Frazzoli, C.,Orisakwe, O.E., 2018. Street foods exacerbate effects of the environmental burden of polycyclic aromatic hydrocarbons (PAHs) in Nigeria. Environmental science and pollution research international. 25, 5529-5538. https://doi.org/10.1007/s11356-017-0894-1.

Faught, E.L.,McLaren, L.,Kirkpatrick, S.I.,Hammond, D.,Minaker, L.M.,Raine, K.D.,Olstad, D.L., 2019. Socioeconomic Disadvantage across the Life Course Is Associated with Diet Quality in Young Adulthood. 
Nutrients. 11. https://doi.org/10.3390/nu11020242.

Gao, M.,Li, Y.,Zheng, A.,Xue, X.,Chen, L.,Kong, Y., 2014. Lymphocyte oxidative stress/genotoxic effects are related to serum IgG and IgA levels in coke oven workers. ScientificWorldJournal. 2014, 801346. https://doi.org/10.1155/2014/801346.

Gou, P.,Chang, X.,Ye, Z.,Yao, Y.,Nguyen, P.K.,Hammond, S.K.,Wang, J.,Liu, S., 2017. A pilot study comparing T-regulatory cell function among healthy children in different areas of Gansu, China. Environmental science and pollution research international. 24, 22579-22586. https://doi.org/10.1007/s11356-017$\underline{9907-3}$

Ghosh, S.S.,Wang, J.,Yannie, P.J.,Ghosh, S., 2020. Intestinal Barrier Dysfunction, LPS Translocation, and Disease Development. J Endocr Soc. 4, bvz039. https://doi.org/10.1210/jendso/bvz039.

Giannasca, P.J.,Giannasca, K.T.,Leichtner, A.M.,Neutra, M.R., 1999. Human intestinal M cells display the sialyl Lewis A antigen. Infect Immun. 67, 946-953. https://doi.org/10.1128/IAI.67.2.946-953.1999.

Gullberg, E.,Leonard, M.,Karlsson, J.,Hopkins, A.M.,Brayden, D.,Baird, A.W.,Artursson, P., 2000. Expression of specific markers and particle transport in a new human intestinal M-cell model. Biochem Biophys Res Commun. 279, 808-813. https://doi.org/10.1006/bbrc.2000.4038.

Gullberg, E.,Soderholm, J.D., 2006. Peyer's patches and M cells as potential sites of the inflammatory onset in Crohn's disease. Ann N Y Acad Sci. 1072, 218-232. https://doi.org/10.1196/annals.1326.028.

Gunter, M.J.,Divi, R.L.,Kulldorff, M.,Vermeulen, R.,Haverkos, K.J.,Kuo, M.M.,Strickland, P.,Poirier, M.C.,Rothman, N.,Sinha, R., 2007. Leukocyte polycyclic aromatic hydrocarbon-DNA adduct formation and colorectal adenoma. Carcinogenesis. 28, 1426-1429. https://doi.org/10.1093/carcin/bgm022.

Guo, Y.Y.,Huo, X.,Wu, K.S.,Liu, J.X.,Zhang, Y.L.,Xu, X.J., 2012. Carcinogenic polycyclic aromatic hydrocarbons in umbilical cord blood of human neonates from Guiyu, China. Sci Total Environ. 427, 3540. https://doi.org/10.1016/j.scitotenv.2012.04.007.

Henkler, F.,Stolpmann, K.,Luch, A., 2012. Exposure to polycyclic aromatic hydrocarbons: bulky DNA adducts and cellular responses. Exp Suppl. 101, 107-131. https://doi.org/10.1007/978-3-7643-8340-4_5.

Hu, C.,Hou, J.,Zhou, Y.,Sun, H.,Yin, W.,Zhang, Y.,Wang, X.,Wang, G.,Chen, W.,Yuan, J., 2018a. Association of polycyclic aromatic hydrocarbons exposure with atherosclerotic cardiovascular disease risk: A role of mean platelet volume or club cell secretory protein. Environ Pollut. 233, 45-53.

https://doi.org/10.1016/j.envpol.2017.10.042.

Huang, X.,Deng, X.,Li, W.,Liu, S.,Chen, Y.,Yang, B.,Liu, Q., 2019. Internal exposure levels of polycyclic aromatic hydrocarbons in children and adolescents: a systematic review and meta-analysis. Environ Health Prev Med. 24, 50. https://doi.org/10.1186/s12199-019-0805-9. 
Huang, X.F.,Xu, X.J.,Dai, Y.F.,Cheng, Z.H.,Zheng, X.B.,Huo, X., 2020. Association of prenatal exposure to PAHs with anti-Mullerian hormone (AMH) levels and birth outcomes of newborns. Sci Total Environ. 723. https://doi.org/10.1016/j.scitotenv.2020.138009.

Huang, X.J.,Zhou, Y.,Cui, X.Q.,Wu, X.J.,Yuan, J.,Xie, J.G.,Chen, W.H., 2018. Urinary polycyclic aromatic hydrocarbon metabolites and adult asthma: a case-control study. Sci Rep-Uk. 8. https://doi.org/10.1038/s41598-018-26021-3.

Huo, X.,Wu, Y.,Xu, L.,Zeng, X.,Qin, Q.,Xu, X., 2019. Maternal urinary metabolites of PAHs and its association with adverse birth outcomes in an intensive e-waste recycling area. Environ Pollut. 245, 453-461. https://doi.org/10.1016/j.envpol.2018.10.098.

larumov, N.,Ignatov, A.,Viiachki, I., 1998. [The pre- and postoperative monitoring of the immunological indices and tumor markers in colorectal carcinoma]. Khirurgiia (Sofiia). 51, 42-48.

Jasim, S.M.,Salim, S.A.-d.,Reda, M.M., 2008. A study of carbohydrate antigen 19-9 level in patients with benign and malignant colorectal tumors in relation to the level of immunoglobulins. Iraqi Journal of Medical Sciences. 6, 104-111.

Jeng, H.A.,Pan, C.H.,Diawara, N.,Chang-Chien, G.P.,Lin, W.Y.,Huang, C.T.,Ho, C.K.,Wu, M.T., 2011. Polycyclic aromatic hydrocarbon-induced oxidative stress and lipid peroxidation in relation to immunological alteration. Occup Environ Med. 68, 653-658. https://doi.org/10.1136/oem.2010.055020.

Kamal, A.,Malik, R.N.,Martellini, T.,Cincinelli, A., 2014. PAH exposure biomarkers are associated with clinico-chemical changes in the brick kiln workers in Pakistan. Sci Total Environ. 490, 521-527. https://doi.org/10.1016/j.scitotenv.2014.05.033.

Karakaya, A.,Yücesoy, B.,Turhan, A.,Erdem, O.,Burgaz, S.,Karakaya, A.E., 1999. Investigation of some immunological functions in a group of asphalt workers exposed to polycyclic aromatic hydrocarbons. Toxicology. 135, 43-47. https://doi.org/10.1016/S0300-483X(99) 00048-7.

Karimi, P.,Peters, K.O.,Bidad, K.,Strickland, P.T., 2015. Polycyclic aromatic hydrocarbons and childhood asthma. Eur J Epidemiol. 30, 91-101. https://doi.org/10.1007/s10654-015-9988-6.

Keir, J.L.A.,Cakmak, S.,Blais, J.M.,White, P.A., 2020. The influence of demographic and lifestyle factors on urinary levels of PAH metabolites-empirical analyses of Cycle 2 (2009-2011) CHMS data. J Expo Sci Env Epid. https://doi.org/10.1038/s41370-020-0208-4.

Kim, K.H.,Jahan, S.A.,Kabir, E.,Brown, R.J., 2013. A review of airborne polycyclic aromatic hydrocarbons (PAHs) and their human health effects. Environ Int. 60, 71-80.

https://doi.org/10.1016/j.envint.2013.07.019.

Kim, S.S.,Vuong, A.M.,Dietrich, K.N.,Chen, A., 2021. Proximity to traffic and exposure to polycyclic aromatic hydrocarbons in relation to Attention Deficit Hyperactivity Disorder and conduct disorder in U.S. 
children. International journal of hygiene and environmental health. 232, 113686.

https://doi.org/10.1016/j.ijheh.2020.113686.

Kobayashi, N.,Takahashi, D.,Takano, S.,Kimura, S.,Hase, K., 2019. The Roles of Peyer's Patches and Microfold Cells in the Gut Immune System: Relevance to Autoimmune Diseases. Front Immunol. 10, 2345. https://doi.org/10.3389/fimmu.2019.02345.

Lao, J.Y.,Xie, S.Y.,Wu, C.C.,Bao, L.J.,Tao, S.,Zeng, E.Y., 2018. Importance of Dermal Absorption of Polycyclic Aromatic Hydrocarbons Derived from Barbecue Fumes. Environmental science \& technology. 52, 8330-8338. https://doi.org/10.1021/acs.est.8b01689

Lauer, F.T.,Parvez, F.,Factor-Litvak, P.,Liu, X.,Santella, R.M.,Islam, T.,Eunus, M.,Alam, N.,Hasan, A.,Rahman, M.,Ahsan, H.,Graziano, J.,Burchiel, S.W., 2019. Changes in human peripheral blood mononuclear cell (HPBMC) populations and T-cell subsets associated with arsenic and polycyclic aromatic hydrocarbon exposures in a Bangladesh cohort. PLoS One. 14, e0220451.

https://doi.org/10.1371/journal.pone.0220451.

Li, Y.,Jin, L.,Chen, T., 2020. The Effects of Secretory IgA in the Mucosal Immune System. Biomed Res Int. 2020, 2032057. https://doi.org/10.1155/2020/2032057.

Liu, J.,Cui, H.,Peng, X.,Fang, J.,Zuo, Z.,Deng, J.,Wang, H.,Wu, B.,Deng, Y.,Wang, K., 2013. Decreased IgA+ B cells population and IgA, IgG, IgM contents of the cecal tonsil induced by dietary high fluorine in broilers. Int J Environ Res Public Health. 10, 1775-1785. https://doi.org/10.3390/ijerph10051775.

Liu, R.,Ma, S.,Yu, Y.,Li, G.,Yu, Y.,An, T., 2020. Field study of PAHs with their derivatives emitted from e-waste dismantling processes and their comprehensive human exposure implications. Environ Int. 144, 106059. https://doi.org/10.1016/j.envint.2020.106059.

Lu, S.Y.,Li, Y.X.,Zhang, J.Q.,Zhang, T.,Liu, G.H.,Huang, M.Z.,Li, X.,Ruan, J.J.,Kannan, K.,Qiu, R.L., 2016. Associations between polycyclic aromatic hydrocarbon (PAH) exposure and oxidative stress in people living near e-waste recycling facilities in China. Environment International. 94, 161-169. https://doi.org/10.1016/j.envint.2016.05.021.

Lugering, A.,Floer, M.,Lugering, N.,Cichon, C.,Schmidt, M.A.,Domschke, W.,Kucharzik, T., 2004. Characterization of $\mathrm{M}$ cell formation and associated mononuclear cells during indomethacin-induced intestinal inflammation. Clin Exp Immunol. 136, 232-238. https://doi.org/10.1111/j.13652249.2004.02438.x.

Manoli, E.,Kouras, A.,Karagkiozidou, O.,Argyropoulos, G.,Voutsa, D.,Samara, C., 2016. Polycyclic aromatic hydrocarbons (PAHs) at traffic and urban background sites of northern Greece: source apportionment of ambient PAH levels and PAH-induced lung cancer risk. Environmental science and pollution research international. 23, 3556-3568. https://doi.org/10.1007/s11356-015-5573-5 
Mantey, J.A.,Rekhadevi, P.V.,Diggs, D.L.,Ramesh, A., 2014. Metabolism of benzo(a)pyrene by subcellular fractions of gastrointestinal (GI) tract and liver in Apc(Min) mouse model of colon cancer. Tumour Biol. 35, 4929-4935. https://doi.org/10.1007/s13277-014-1647-0.

Nagai, M.,Noguchi, R.,Takahashi, D.,Morikawa, T.,Koshida, K.,Komiyama, S.,Ishihara, N.,Yamada, T.,Kawamura, Y.I.,Muroi, K.,Hattori, K.,Kobayashi, N.,Fujimura, Y.,Hirota, M.,Matsumoto, R.,Aoki, R.,TamuraNakano, M.,Sugiyama, M.,Katakai, T.,Sato, S.,Takubo, K.,Dohi, T.,Hase, K., 2019. Fasting-Refeeding Impacts Immune Cell Dynamics and Mucosal Immune Responses. Cell. 178, 1072-+. https://doi.org/10.1016/j.cell.2019.07.047.

Navin, T.,Weber, R.,Vugia, D.,Rimland, D.,Roberts, J.,Addiss, D.,Visvesvara, G.,Wahlquist, S.,Hogan, S.,Gallagher, L.,Juranek, D.,Schwartz, D.,Wilcox, C.,Stewart, J.,Thompson, S.,Bryan, R., 1999. Declining CD4+ T-lymphocyte counts are associated with increased risk of enteric parasitosis and chronic diarrhea: Results of a 3-year longitudinal study. Journal of acquired immune deficiency syndromes and human retrovirology : official publication of the International Retrovirology Association. 20, 154-159. https://doi.org/10.1097/00042560-199902010-00007

Nethery, E.,Wheeler, A.J.,Fisher, M.,Sjödin, A.,Li, Z.,Romanoff, L.C.,Foster, W.,Arbuckle, T.E., 2012. Urinary polycyclic aromatic hydrocarbons as a biomarker of exposure to PAHs in air: a pilot study among pregnant women. Journal of exposure science \& environmental epidemiology. 22, 70-81. https://doi.org/10.1038/jes.2011.32.

Ohno, H., 2016. Intestinal M cells. J Biochem. 159, 151-160. https://doi.org/10.1093/jb/mvv121.

Oliveira, M.,Slezakova, K.,Delerue-Matos, C.,Pereira, M.C.,Morais, S., 2019. Children environmental exposure to particulate matter and polycyclic aromatic hydrocarbons and biomonitoring in school environments: A review on indoor and outdoor exposure levels, major sources and health impacts. Environment International. 124, 180-204. https://doi.org/https://doi.org/10.1016/j.envint.2018.12.052.

Oliveira, M.,Capelas, S.,Delerue-Matos, C.,Morais, S., 2020. Grill Workers Exposure to Polycyclic Aromatic Hydrocarbons: Levels and Excretion Profiles of the Urinary Biomarkers. Int J Environ Res Public Health. 18. https://doi.org/10.3390/ijerph18010230.

Onyemauwa, F.,Rappaport, S.M.,Sobus, J.R.,Gajdosova, D.,Wu, R.,Waidyanatha, S., 2009. Using liquid chromatography-tandem mass spectrometry to quantify monohydroxylated metabolites of polycyclic aromatic hydrocarbons in urine. J Chromatogr B Analyt Technol Biomed Life Sci. 877, 1117-1125. https://doi.org/10.1016/j.j.jhromb.2009.02.067.

Pérez-Griera, J.,Andreu-Ballester, J.C.,Hueso Zarandieta, A.,García de la Asunción, J.,Masquefa Bondia, S., 2017. A quantitative enzyme-linked immunosorbent assay for quantification of secretory immunoglobulin A in serum. J Immunoassay Immunochem. 38, 67-71. https://doi.org/10.1080/15321819.2016.1216443. 
Poirier, M.C.,Lair, S.,Michaud, R.,Hernandez-Ramon, E.E.,Divi, K.V.,Dwyer, J.E.,Ester, C.D.,Si, N.N.,Ali, M.,Loseto, L.L.,Raverty, S.A.,St Leger, J.A.,Van Bonn, W.G.,Colegrove, K.,Burek-Huntington, K.A.,Suydam, R.,Stimmelmayr, R.,Wise, J.P.,Wise, S.S.,Beauchamp, G.,Martineau, D., 2019. Intestinal polycyclic aromatic hydrocarbon-DNA adducts in a population of beluga whales with high levels of gastrointestinal cancers. Environ Mol Mutagen. 60, 29-41. https://doi.org/10.1002/em.22251.

Prince, U., 2015. Environmental effects of polycyclic aromatic hydrocarbons. Journal of Natural Sciences Research 5 (7), 117-131.

Ragupathi, G.,Damani, P.,Srivastava, G.,Srivastava, O.,Sucheck, S.J.,Ichikawa, Y.,Livingston, P.O., 2009. Synthesis of sialyl Lewis(a) (sLe (a), CA19-9) and construction of an immunogenic sLe(a) vaccine. Cancer Immunol Immunother. 58, 1397-1405. https://doi.org/10.1007/s00262-008-0654-7.

Ramirez, N.,Cuadras, A.,Rovira, E.,Marce, R.M.,Borrull, F., 2011. Risk assessment related to atmospheric polycyclic aromatic hydrocarbons in gas and particle phases near industrial sites. Environ Health Perspect. 119, 1110-1116. https://doi.org/10.1289/ehp.1002855.

Ren, W.,Wang, K.,Yin, J.,Chen, S.,Liu, G., Tan, B.,Wu, G.,Bazer, F.W.,Peng, Y.,Yin, Y., 2016. Glutamine-Induced Secretion of Intestinal Secretory Immunoglobulin A: A Mechanistic Perspective. Front Immunol. 7, 503. https://doi.org/10.3389/fimmu.2016.00503.

Rengarajan, T.,Rajendran, P.,Nandakumar, N.,Lokeshkumar, B.,Rajendran, P.,Nishigaki, I., 2015. Exposure to polycyclic aromatic hydrocarbons with special focus on cancer. Asian Pacific Journal of Tropical Biomedicine. 5, 182-189. https://doi.org/10.1016/S2221-1691(15)

Roshandel, G.,Semnani, S.,Malekzadeh, R.,Dawsey, S.M., 2012. Polycyclic aromatic hydrocarbons and esophageal squamous cell carcinoma. Arch Iran Med. 15, 713-722. https://doi.org/0121511/AIM.0013.

Roslund, M.I.,Rantala, S.,Oikarinen, S.,Puhakka, R.,Hui, N.,Parajuli, A.,Laitinen, O.H.,Hyoty, H.,Rantalainen, A.L.,Sinkkonen, A.,team, A., 2019. Endocrine disruption and commensal bacteria alteration associated with gaseous and soil PAH contamination among daycare children. Environ Int. 130, 104894. https://doi.org/10.1016/j.envint.2019.06.004.

Roslund, M.I.,Puhakka, R.,Grönroos, M.,Nurminen, N.,Oikarinen, S.,Gazali, A.M.,Cinek, O.,Kramná, L.,Siter, N.,Vari, H.K.,Soininen, L.,Parajuli, A.,Rajaniemi, J.,Kinnunen, T.,Laitinen, O.H.,Hyöty, H.,Sinkkonen, A., 2020. Biodiversity intervention enhances immune regulation and health-associated commensal microbiota among daycare children. Science advances. 6. https://doi.org/10.1126/sciadv.aba2578.

Shiue, I., 2016. Urinary polyaromatic hydrocarbons are associated with adult celiac disease and kidney stones: USA NHANES, 2011-2012. Environmental science and pollution research international. 23, 39713977. https://doi.org/10.1007/s11356-015-5980-7. 
Szczeklik, A.,Szczeklik, J.,Galuszka, Z.,Musial, J.,Kolarzyk, E.,Targosz, D., 1994. Humoral immunosuppression in men exposed to polycyclic aromatic hydrocarbons and related carcinogens in polluted environments. Environ Health Perspect. 102, 302-304. https://doi.org/10.1289/ehp.94102302.

Wang, Q.,Xu, X.,Zeng, Z.,Hylkema, M.N.,Cai, Z.,Huo, X., 2020a. PAH exposure is associated with enhanced risk for pediatric dyslipidemia through serum SOD reduction. Environ Int. 145, 106132.

https://doi.org/10.1016/j.envint.2020.106132.

Wang, Q.,Xu, X.,Zeng, Z.,Zheng, X.,Ye, K.,Huo, X., 2020b. Antioxidant alterations link polycyclic aromatic hydrocarbons to blood pressure in children. Sci Total Environ. 732, 138944.

https://doi.org/10.1016/j.scitotenv.2020.138944.

Xu, X.,Yekeen, T.A.,Xiao, Q.,Wang, Y.,Lu, F.,Huo, X., 2013. Placental IGF-1 and IGFBP-3 expression correlate with umbilical cord blood PAH and PBDE levels from prenatal exposure to electronic waste. Environ Pollut. 182, 63-69. https://doi.org/10.1016/j.envpol.2013.07.005.

Xu, X.J.,Liu, J.X.,Huang, C.Y.,Lu, F.F.,Chiung, Y.M.,Huo, X., 2015. Association of polycyclic aromatic hydrocarbons (PAHs) and lead co-exposure with child physical growth and development in an e-waste recycling town. Chemosphere. 139, 295-302. https://doi.org/10.1016/j.chemosphere.2015.05.080.

Yang, B.,Deng, Q.,Zhang, W.,Feng, Y.,Dai, X.,Feng, W.,He, X.,Huang, S.,Zhang, X.,Li, X.,Lin, D.,He, M.,Guo, H.,Sun, H.,Yuan, J.,Lu, J.,Hu, F.B.,Zhang, X.,Wu, T., 2016. Exposure to Polycyclic Aromatic Hydrocarbons, Plasma Cytokines, and Heart Rate Variability. Sci Rep. 6, 19272. https://doi.org/10.1038/srep19272.

Yang, L.L.,Zhou, Y.,Sun, H.Z.,Lai, H.P.,Liu, C.Y.,Yan, K.,Yuan, J.,Wu, T.C.,Chen, W.H.,Zhang, X.M., 2014. Doseresponse relationship between polycyclic aromatic hydrocarbon metabolites and risk of diabetes in the general Chinese population. Environ Pollut. 195, 24-30. https://doi.org/10.1016/j.envpol.2014.08.012.

Yaya, S.,Hudani, A.,Udenigwe, O.,Shah, V.,Ekholuenetale, M.,Bishwajit, G., 2018. Improving Water, Sanitation and Hygiene Practices, and Housing Quality to Prevent Diarrhea among Under-Five Children in Nigeria. Trop Med Infect Dis. 3. https://doi.org/10.3390/tropicalmed3020041.

Yilmaz, B.,Ssempebwa, J.,Mackerer, C.R.,Arcaro, K.F.,Carpenter, D.O., 2007. Effects of polycyclic aromatic hydrocarbon-containing oil mixtures on generation of reactive oxygen species and cell viability in MCF-7 breast cancer cells. Journal of toxicology and environmental health Part A. 70, 1108-1115. https://doi.org/10.1080/15287390701208545

Zeng, Z.J.,Huo, X.,Wang, Q.H.,Wang, C.Y.,Hylkema, M.N.,Xu, X.J., 2020. PM2.5-bound PAHs exposure linked with low plasma insulin-like growth factor 1 levels and reduced child height. Environment International. 138. https://doi.org/10.1016/j.envint.2020.105660.

Zeng, Z.,Huo, X.,Zhang, Y.,Xiao, Z.,Zhang, Y.,Xu, X., 2018. Lead exposure is associated with risk of impaired coagulation in preschool children from an e-waste recycling area. Environmental science and 
pollution research international. 25, 20670-20679. https://doi.org/10.1007/s11356-018-2206-9

Zhang, B.,Pan, B.L.,Zhao, X.Y.,Fu, Y.,Li, X.J.,Yang, A.M.,Li, Q.,Dong, J.,Nie, J.S.,Yang, J., 2020a. The interaction effects of smoking and polycyclic aromatic hydrocarbons exposure on the prevalence of metabolic syndrome in coke oven workers. Chemosphere. 247. https://doi.org/10.1016/j.chemosphere.2020.125880.

Zhang, H.,Han, Y.,Qiu, X.,Wang, Y.,Li, W.,Liu, J.,Chen, X.,Li, R.,Xu, F.,Chen, W.,Yang, Q.,Fang, Y.,Fan, Y.,Wang, J.,Zhang, H.,Zhu, T., 2020b. Association of internal exposure to polycyclic aromatic hydrocarbons with inflammation and oxidative stress in prediabetic and healthy individuals. Chemosphere. 253, 126748. https://doi.org/10.1016/j.chemosphere.2020.126748.

Zheng, X.B.,Huo, X.,Zhang, Y.,Wang, Q.H.,Zhang, Y.L.,Xu, X.J., 2019. Cardiovascular endothelial inflammation by chronic coexposure to lead $(\mathrm{Pb})$ and polycyclic aromatic hydrocarbons from preschool children in an e-waste recycling area. Environ Pollut. 246, 587-596.

https://doi.org/10.1016/j.envpol.2018.12.055.

\section{Tables}

\section{Table 1}

General characteristics of the study population 
N Reference group N Exposed group $p$

Gender (boys/girls)

Age (median (IQR), years)

Height (mean $\pm \mathrm{SD}$, cm)

Weight (median (IQR), kg)

BMI (median (IQR), kg/m2 )

Chest circumference (median (IQR), cm)

Contact with electronic waste $\llbracket$ yes/no $\square$

Diarrhea (never/1 2 times monthly)

Distance between residence and road

$[\mathrm{n}(\%), \mathrm{m}]$

$<10$

$\sim 50$

$\sim 100$

$>100$

Residence within 50m from an e-waste 112 site (yes/no)

Residence as a workshop(yes/no)

Family member daily cigarette

112

consumption [n (\%)]

Non-smoking

$\sim 2$ cigarettes

$\sim 10$ cigarettes

$\sim 20$ cigarettes

$>20$ cigarettes

Father's educational level [n (\%)]

Middle school or lower

Secondary school

High school

College/university

Mother's educational level [n (\%)]

Middle school or lower

Secondary school

High school

College/university

Monthly household income [n (\%), Yuan]

11

113

113

111

\section{$113 \quad 68$ व 60.2 \\ $\square 39.8 \% \square$}

$1134.88(4.37,5.80)$

$113 \quad 109.29 \pm 7.24$

$11318.50(16.50,20.25)$

$11315.49(14.71,16.30)$

$11352.50(50.40,54.95)$

113

109

111

$12 \square 11.65 \% \square / 101$

$\square 89.38 \%$ $\%$

$\begin{array}{lll}119 & 5.11(4.39,5.76) & 0.431^{\mathrm{b}} \\ 119 & 107.13 \pm 7.52 & 0.027 * \mathrm{~b} \\ 119 & 16.50(15.00,19.00) & 0.000^{* b} \\ 118 & 14.93(13.87,15.75) & 0.000^{* b} \\ 116 & 51.25(49.63,53.58) & 0.026^{* b}\end{array}$

119

$33 \square 27.73 \% \square / 86$ ๑72.27\%ם

$0.002 * \mathrm{a}$

$80 \square 70.7 \% \square / 35 \square 29.3$

$0.020 * a$

119

$0.000 * \mathrm{a}$

$48 \square 40.3 \% \square$

$34 \square 28.6 \% \square$

$30 \square 27.03 \% \square$

$22 \square 18.5 \% \square$

$15 \square 12.6 \% \square$

$42 \square 37.83 \% \square$

116

$27 \square 23.28 \% \square / 89$

๑76.72\%ם

$1106 \square 5.5 \% \square / 104 \square 94.5 \% \square$

119

$\%$

118

$0.032 * a$

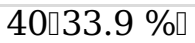

$24 \square 20.3 \% \square$

$20 \square 17.0 \% \square$

$23 \square 19.5 \% \square$

$11 \square 9.3 \% \square$

119

$0.000 * \mathrm{a}$

9075.6\%ロ

$8 \square 6.7 \%$ 口

$12 \square 10.1 \% \square$

$9 \square 7.6 \%$ ㅁ

118

$0.000 * \mathrm{a}$

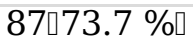

$10 \square 8.5 \% \square$

9⒎6\%ロ

$12 \square 10.2 \% \square$

\begin{tabular}{ll}
$31 \square 27.4 \% \square$ & $87 \square 73.7 \% \square$ \\
\hline $21 \square 18.6 \% \square$ & $10 \square 8.5 \% \square$ \\
$15 \square 13.3 \% \square$ & $9 \square 7.6 \% \square$ \\
$46 \square 40.7 \% \square$ & $12 \square 10.2 \% \square$
\end{tabular}

112

$0.000 * \mathrm{a}$ 
BMI, body mass index. SD, standard deviation. Statistical significance,

$* P<0.05$.

${ }^{a}$ Analysis by Pearson chi-square test.

${ }^{\mathrm{b}}$ Analysis by independent-sample $t$-test.

\section{Table 2}

Urinary PAH metabolite concentrations in e-waste-exposed and reference groups

\begin{tabular}{llll} 
& $\begin{array}{l}\text { Reference group } \\
(\mathrm{N}=113)\end{array}$ & $\begin{array}{l}\text { Exposed group } \\
(\mathrm{N}=119)\end{array}$ & $p$ \\
\hline OH-PAH $(\mu \mathrm{mol} / \mathrm{mmol} \mathrm{Cr})$ & & & \\
/median $(25 \mathrm{th}, 75 \mathrm{th})$ & & & \\
\hline Urine-Cre & $12.48(7.25,26.07)$ & $12.27(6.89,24.12)$ & 0.777 \\
\hline 1-OHNap & $0.18(0.08,0.34)$ & $0.85(0.47,1.51)$ & $0.000^{*}$ \\
\hline 2-OHNap & $3.16(1.58,5.48)$ & $4.49(2.57,6.99)$ & $0.008^{*}$ \\
\hline 2-OHFlu & $0.54(0.26,0.93)$ & $0.64(0.34,1.11)$ & $0.046^{*}$ \\
\hline 9-OHFlu & $1.86(0.82,4.59)$ & $2.31(1.13,5.25)$ & 0.167 \\
\hline 1-OHPhe & $0.77(0.38,1.40)$ & $1.18(0.59,2.05)$ & $0.001^{*}$ \\
\hline 2-OHPhe & $0.89(0.46,1.53)$ & $1.04(0.59,1.82)$ & 0.067 \\
\hline 3-OHPhe & $1.66(1.12,2.53)$ & $1.85(1.22,3.17)$ & 0.081 \\
\hline 4-OHPhe & $0.87(0.46,1.50)$ & $1.06(0.63,1.85)$ & $0.015^{*}$ \\
\hline 9-OHPhe & $0.79(0.36,1.37)$ & $0.87(0.48,1.73)$ & 0.117 \\
\hline 1-OHPyr & $1.26(0.60,3.40)$ & $2.49(1.27,5.49)$ & $0.000^{*}$ \\
\hline 6-OHChr & $0.44(0.23,0.81)$ & $0.56(0.33,0.95)$ & $0.033^{*}$ \\
\hline SOHNap & $3.46(1.72,5.82)$ & $5.43(3.14,7.91)$ & $0.000^{*}$ \\
\hline SOHFlu & $2.50(1.11,5.64)$ & $2.93(1.47,6.06)$ & 0.136 \\
\hline SOHPhe & $4.98(2.75,8.32)$ & $6.15(3.55,10.80)$ & $0.027^{*}$ \\
\hline SPHAs & $13.77(6.65,23.01)$ & $19.20(11.18,32.16 \square$ & $0.002^{*}$ \\
\hline & & &
\end{tabular}

Cre: creatinine

Analysis by independent-sample $t$-test.

$* P<0.05$. 
$* * P<0.01$.

\section{Table 3}

Spearman analysis of the association between urinary PAH metabolites and characteristics of children BMI High Weight Head circumference Chest circumference

\begin{tabular}{|c|c|c|c|c|c|}
\hline 1₫OHNap & प0.219** & $\square 0.211 * *$ & ๑0.307** & 0.002 & प0.199** \\
\hline 2₫OHNap & $\square 0.090$ & $\square 0.245^{* *}$ & $00.250 * *$ & $\square 0.091$ & $\square 0.222 * *$ \\
\hline 2₫OHFlu & $\square 0.078$ & $\square 0.178 * *$ & $\square 0.182 * *$ & $\square 0.036$ & $\square 0.162 *$ \\
\hline 9₫OHFlu & $\square 0.077$ & $\square 0.083$ & $\square 0.099$ & 0.025 & $\square 0.084$ \\
\hline 1₫OHPhe & $\square 0.043$ & $\square 0.232 * *$ & $\square 0.219 * *$ & $\square 0.061$ & $\square 0.180 * *$ \\
\hline 2₫OHPhe & $\square 0.067$ & $\square 0.228^{* *}$ & $\square 0.221 * *$ & $\square 0.090$ & $\square 0.200 * *$ \\
\hline 3₫OHPhe & $\square 0.075$ & $\square 0.196 * *$ & $\square 0.201 * *$ & $\square 0.051$ & ๑0.167* \\
\hline 4₫OHPhe & $\square 0.092$ & $\square 0.205^{* *}$ & $\square 0.216^{* *}$ & $\square 0.051$ & $\square 0.187 * *$ \\
\hline 9₫OHPhe & $\square 0.060$ & प0.204** & प0.190** & 00.068 & $\square 0.175 * *$ \\
\hline 1₫OHPyr & $\square 0.075$ & $\square 0.237 * *$ & $\square 0.254 * *$ & $\square 0.092$ & $\square 0.187 * *$ \\
\hline $6 \llbracket \mathrm{OHChr}$ & $\square 0.077$ & $\square 0.223 * *$ & $\square 0.220 * *$ & $\square 0.091$ & $\square 0.186 * *$ \\
\hline SOHNap & $\square 0.115$ & $\square 0.253^{* *}$ & $\square 0.272 * *$ & $\square 0.083$ & $\square 0.230 * *$ \\
\hline SOHFlu & $\square 0.074$ & $\square 0.096$ & $\square 0.107$ & 0.022 & $\square 0.092$ \\
\hline SOHPhe & $\square 0.070$ & $\square 0.221 * *$ & $\square 0.218^{* *}$ & $\square 0.064$ & $\square 0.190 * *$ \\
\hline SOHPHAs & $\square 0.085$ & $\square 0.213^{* *}$ & प0.219** & $\square 0.048$ & $\square 0.182 * *$ \\
\hline
\end{tabular}

$* P<0.05$.

$* * P<0.01$

\section{Table 4}

Spearman correlation analysis between urinary metabolites of PAHs and related factors 
Related factors

\begin{tabular}{|c|c|c|c|c|c|}
\hline & $r_{s}$ & $r_{\mathrm{s}}$ & $r_{\mathrm{s}}$ & $r_{s}$ & $r_{\mathrm{s}}$ \\
\hline Electronic waste contact & $0.207 * *$ & 0.095 & 0.105 & 0.058 & 0.095 \\
\hline Residence as a workshop & $0.237 * *$ & 0.119 & 0.126 & 0.078 & 0.119 \\
\hline Distance between residence and road & $-0.271 * *$ & -0.129 & $-0.138 *$ & -0.093 & $-0.133^{*}$ \\
\hline Residence within $50 \mathrm{~m}$ from an e-waste site & $0.161^{*}$ & 0.092 & 0.063 & 0.065 & 0.070 \\
\hline Family member cigarette smoker & $0.136^{*}$ & 0.057 & 0.079 & 0.041 & 0.061 \\
\hline Father's educational level & $-0.416 * *$ & $-0.217 * *$ & $-0.214^{* *}$ & $-0.149 *$ & $-0.201 * *$ \\
\hline Mother's educational level & $-0.343 * *$ & $-0.183 * *$ & $-0.210 * *$ & $-0.133 * *$ & $-0.186 * *$ \\
\hline Monthly household income & 0.073 & 0.095 & 0.095 & 0.101 & 0.097 \\
\hline
\end{tabular}

\section{Figures}
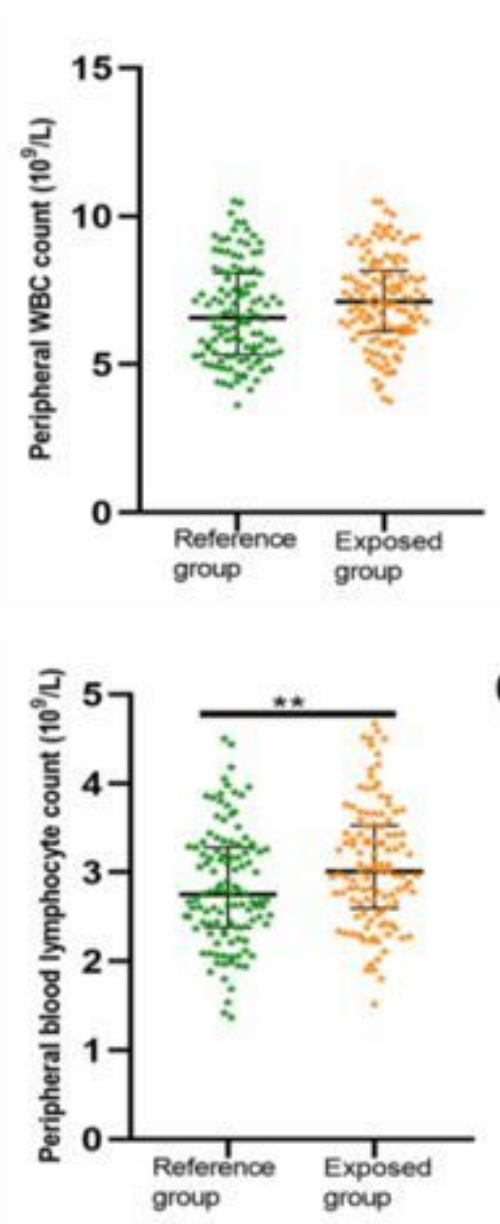

1-OHNap 1-OHPyr S OHNap S OHPhe SOHPAHs

$$
\mathrm{r}_{\mathrm{S}}
$$

$* P<0.05$

** $P<0.01$
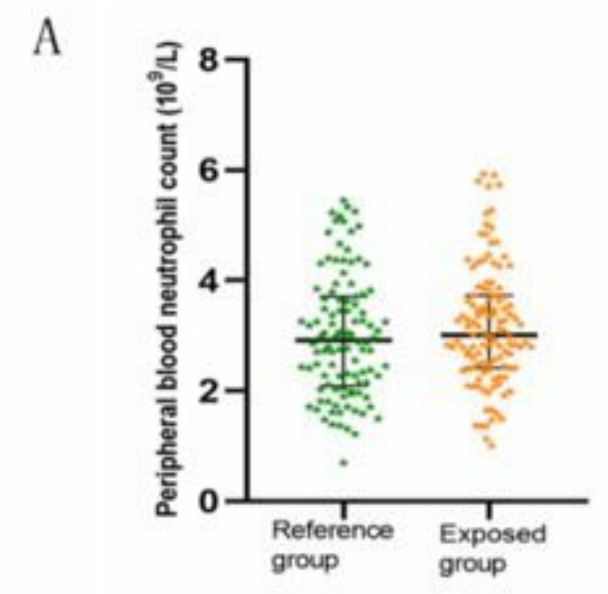

B

C

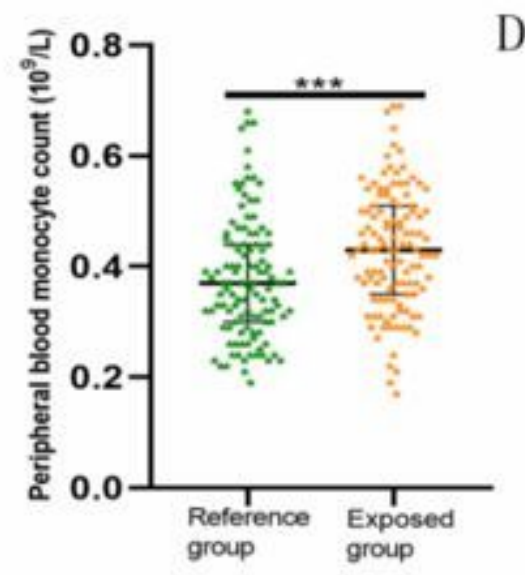


Figure 1

White blood cells, neutrophils, lymphocytes and monocytes between the two groups Reference group, $\mathrm{n}$ =113; exposed group, $n=119$. A: Results are presented as mean \pm standard deviation, analyzed by independent-sample t-test. B, C and D: Results are presented as median (interquartile range), analyzed by the Mann-Whitney $U$ test. Values of ${ }^{*} P<0.05,{ }^{*} P<0.01$, ${ }^{\star \star \star} P<0.001$ were considered statistically significant.

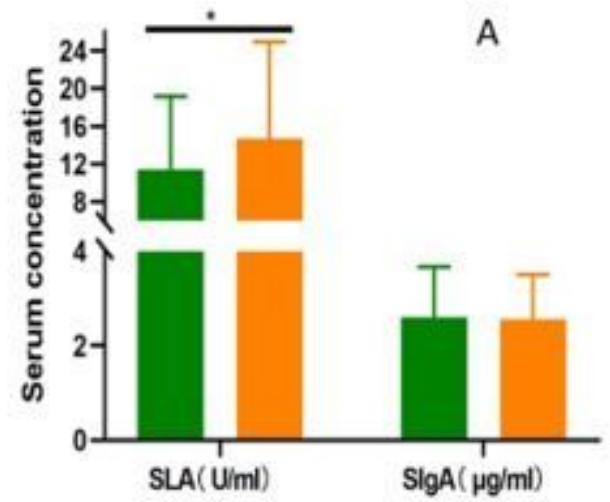

Reference group

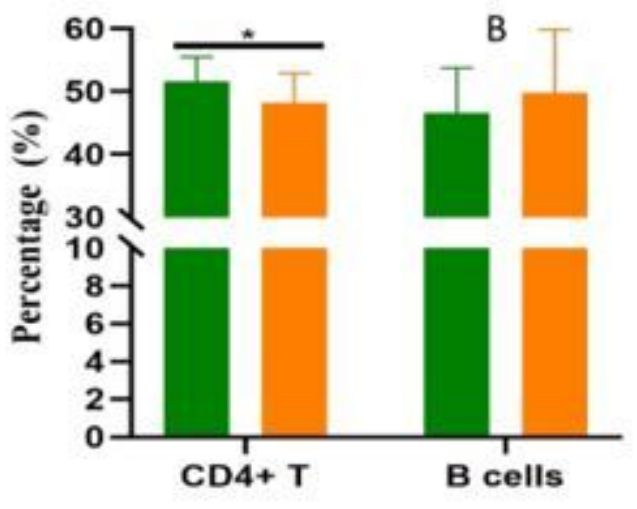

Exposed group

\section{Figure 2}

Biomarkers in exposed and reference groups A: Serum SLA and slgA concentration in the two groups (SLA: exposed group, $n=108$; reference group, $n=105$; slgA: exposed group, $n=113$; reference group, $n=$ 113); $B$ : Percentage of CD4+ and $B$ cells between the two groups (exposed group, $n=113$; reference group, $n=119$ ). Results are presented as mean \pm standard deviation (median interquartile range), obtained with an independent-sample t-test; values of $* \mathrm{P}<0.05$ were considered statistically significant. 

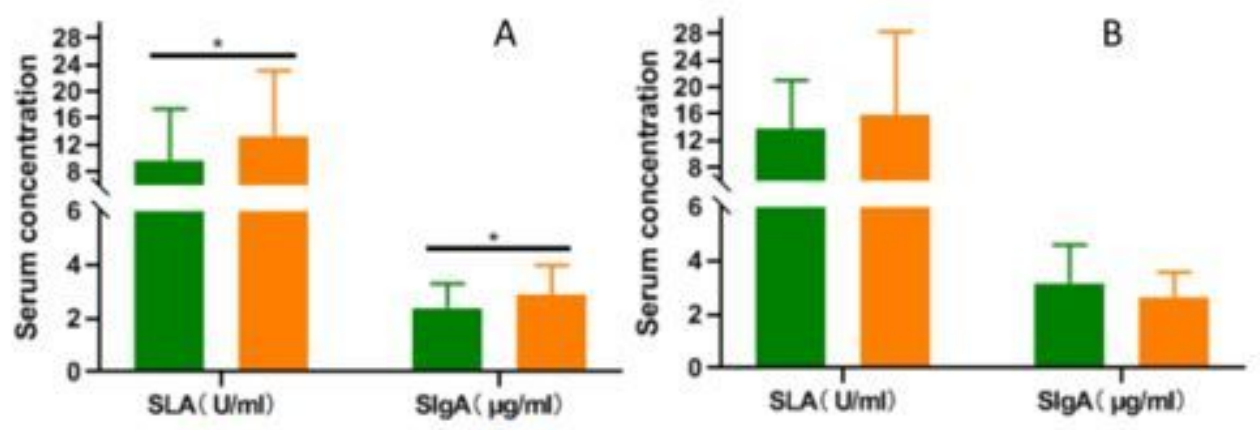

Reference group Exposed group
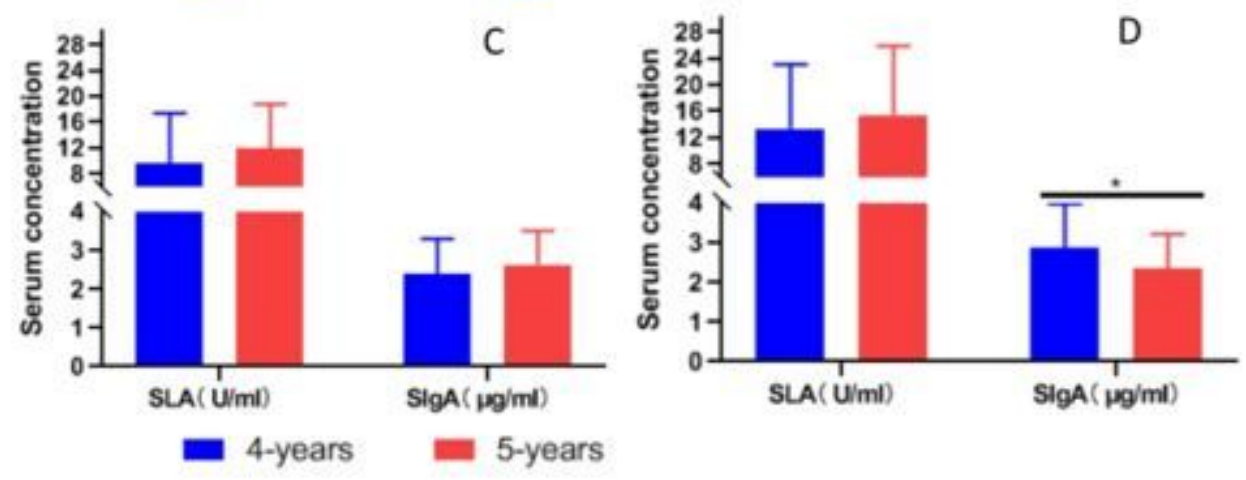

\section{Figure 3}

Subgroup analysis Serum SLA and slgA concentration of 4- and 5-year-old children. A: 4-year-oldgroup (SLA: exposed group, $n=31$; reference group, $n=42$; slgA: exposed group, $n=38$; reference group, $n=45$ ), B: 5-year-old group (SLA: exposed group, $n=46$; reference group, $n=31$; slgA: exposed group, $n=40$; reference group, $n=34$ ). C: Reference group (SLA: 4-year-old group, $n=42 ; 5$-year-old group, $n=31$; slgA: 4-year-old group, $n=45$; 5-year-old group, $n=34$ ), $D$ : Exposed group (SLA: 4-year-old group, $n=31$; 5-yearold group, $n=46$; slgA: 4-year-old group, $n=38$; 5-year-old group, $n=40$ ). Results are presented as median (interquartile range), analyzed by the Mann-Whitney $U$ test. Values of $* P<0.05$ indicate statistical significance. 


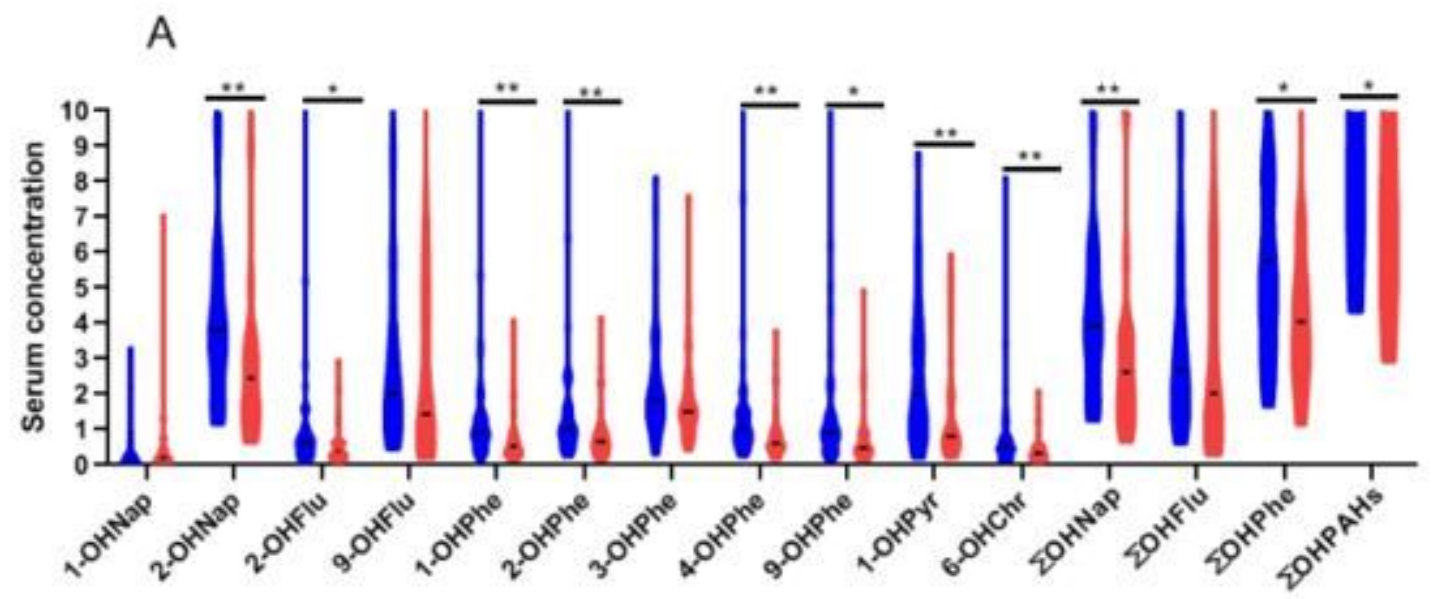

B

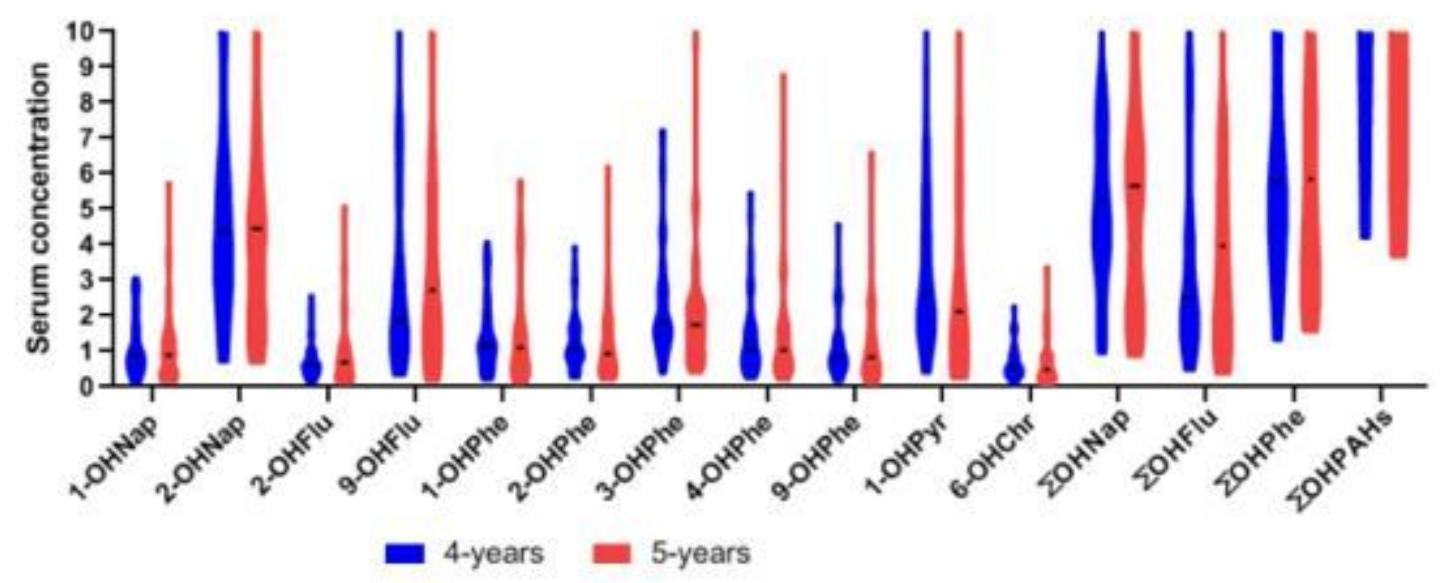

Figure 4

Subgroup analysis of urinary PAH metabolite concentrations $(\mu \mathrm{g} / \mathrm{g}$ Cre) of 4 - and 5-year-old children. A:Reference group (4-year-old group, $n=45 ; 5$-year-old group, $n=36$ ). B: Exposed group (4-year-old group, $n=38 ; 5$-year-old group, $n=46$ ). Analysis by independent-sample t-test. Values of ${ }^{*} P<0.05,{ }^{\star} * P<0.01$ were considered statistically significant 


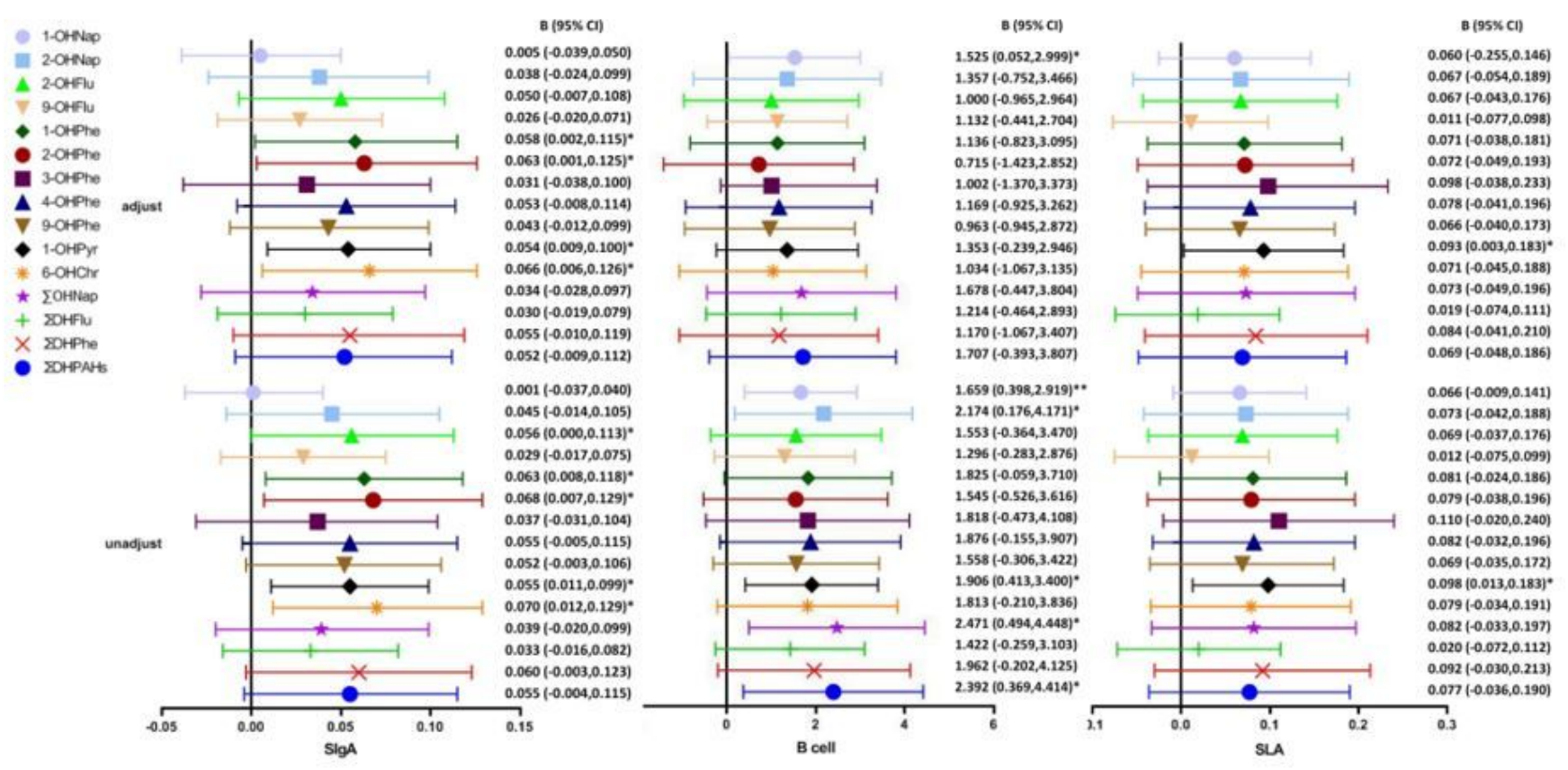

\section{Figure 5}

Effect estimates and 95\% confidence intervals for OH-PAHs with slgA, SLA and B cells. Adjusted model adjusting for gender, age, BMI, contact with e-waste, parental educational level, and monthly household income. BMI, body mass index; $\mathrm{B}$, unstandardized coefficient; $\mathrm{Cl}$, confidence interval. Values of $* \mathrm{P}<0.05$, $\star \star P<0.01$ indicate statistical significance.

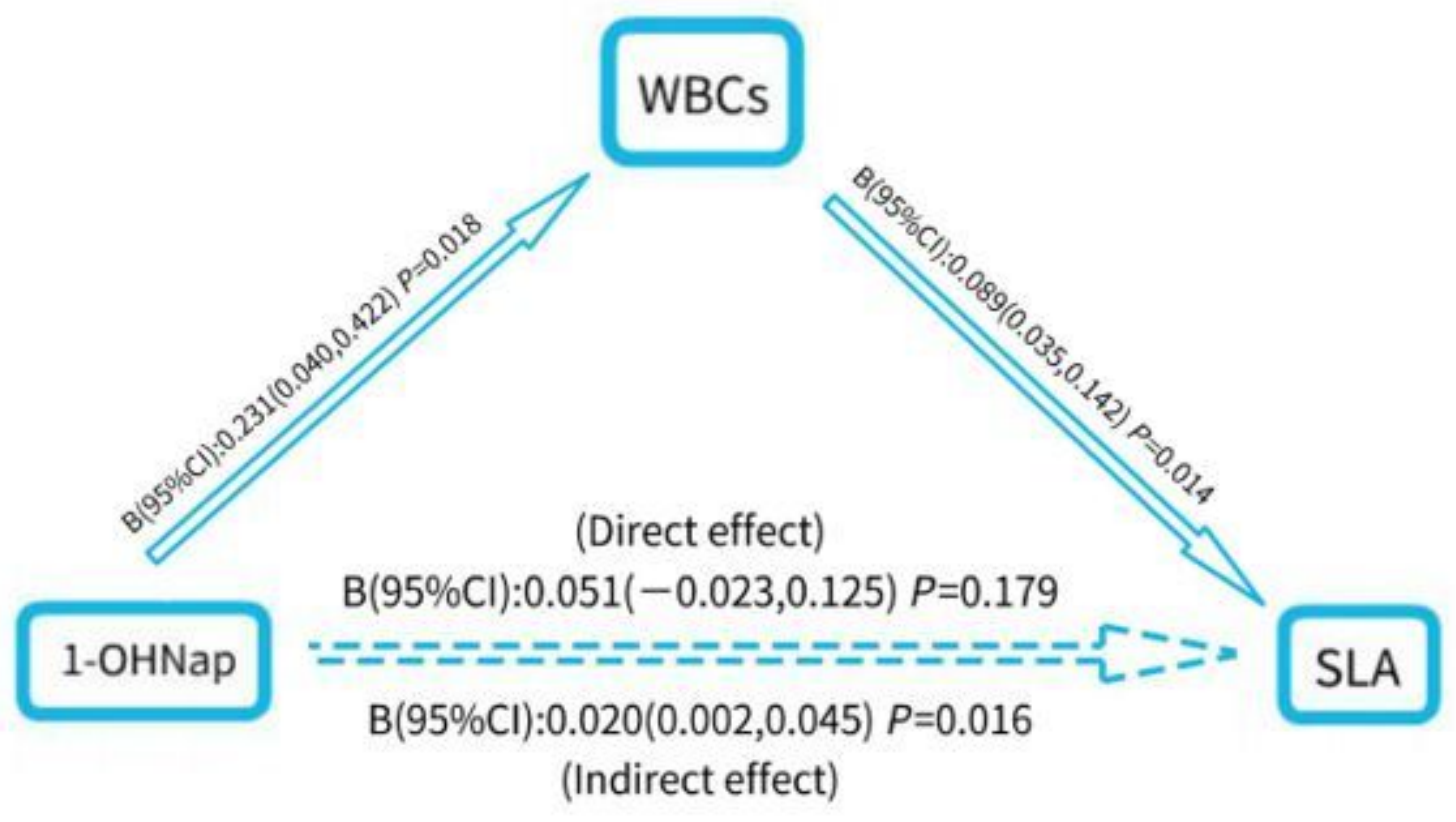

Figure 6 
Mediation effect of WBCs on the relationship between 1-OHNap and SLA. B, unstandardized coefficient; $\mathrm{Cl}$, confidence intervalखBMl; 5000 bootstrap samples; $\mathrm{n}=203$. Statistical significance, $\mathrm{P}<0.05$. 